\title{
Development of a Process for Detecting Inconsistencies between Financial Statements and Financial Transactions (Deals) Aimed at Identifying Signs of Money Laundering
}

\section{Garaschenko A. A. ${ }^{1}$, Nasonov E. V. ${ }^{2}$, and Leonov P. Y. ${ }^{1}$}

${ }^{1}$ National Research Nuclear University MEPhl (Moscow Engineering Physics Institute), Kashirskoe shosse 31, Moscow, 115409, Russia

${ }^{2}$ Counselor of the Department Accounting Office of the President of the Russian Federation, Moscow, Russia

\section{Abstract}

The problem of money-laundering is still valid in the Russian Federation. With the increasing role of the State in the economy, this question becomes particularly significant. Of course, monitoring of the funds movement plays a significant role, in

Corresponding Author:

Leonov P. Y.

p.u.leonov@gmail.com

Received: 11 December 2017

Accepted: 20 January 2018

Published: 13 February 2018

Publishing services provided by Knowledge $\mathrm{E}$

(c) Garaschenko A. A. et al. This article is distributed under the

terms of the Creative Commons

Attribution License, which

permits unrestricted use and

redistribution provided that the

original author and source are credited.

Selection and Peer-review under the responsibility of the FinTech and RegTech: Possibilities, Threats and Risks of Financial Technologies Conference Committee. particular, for companies, recipients of budgetary funds, including providers of the State Defense order (GOZ).

To date, there is no generally accepted method, which would allow a high degree of probability to identify signs of money laundering.

This article first describes how to detect signs of money-laundering on the basis of a comparison of the data of financial statements with bank operations data.

Elaborated process was tested on the example of relevant data of thirty businesses complying with orders under the contracts with the Ministry of Defence of the Russian Federation in 2013.

On the basis of the obtained results recommendations for the improvement of the elaborated process were formulated and the scope of its possible use was identified.

Keywords: money laundering, the process approach, fraud, financial reporting

\section{Introduction}

Basis for decision-making by the interested users is the accounting (financial) statements (BFO), which as a source of information of data on property and financial situation of the organization and the results of its economic activities based on the accounting data on statutory forms [1]. 
The objective of financial statements is to gather the credentials for the reporting period and their presentation in visual form for the interested users, who can be the owners of economic agents and other persons in accordance with the legislation of the Russian Federation.

Methods for the preliminary assessment of the financial accounting quality is currently being developed and widely used, which guarantees correct compliance with all requirements in the preparation of the accounting information [10, p. 6]. Concrete results in the field of checking the quality of the accounting and financial department show that based on some complex procedures, financial statement analysis, there is an opportunity to form an opinion on the reliability of the accounting information.

However, the use of such methods is not able to fully provide sufficient confidence that all of the distortions have been identified [2].

Causes of the distortion of financial statements data are by nature diverse and range from weak internal control systems of the economic entity [11], to the deliberate falsification of accounting information in order to conceal the criminal side of the business.

\section{Analytical part}

Many experts say that to date, "offences involving distortion of accounting (financial) statements, occupy one of the first places among the offences of economic nature" [12]. Moreover, according to the Russian economic crime survey", conducted by PricewaterhouseCoopers [3], the problem of concealing misappropriation of assets by manipulating the balance sheet information, occupies a leading position not only in Russia but throughout the world.

Meanwhile, the designated issue has a more significant impact on the economic security of the country, than it might seem at first glance, since misappropriation of assets in most cases is linked to the concealment of facts of legalization of the criminal proceeds [4] and their further transactions into offshore zones [13].

Based on the above, it is a challenge to increase the number of indicators to detect signs of money-laundering. (Some of the most important criteria are presented in Table 2).

In addition to the indicators listed in this document in order to identify operations related to money laundering are:

OKVED code [4]. Each activity must be recorded in the unified State Register of legal entities. 
Therefore, it is possible to make a comparison of the main code with additional, as well as a comparison of the main PARTICIPANTS in OKVED with the code indicated in the financial statements (they must match).

Signs of bad faith on the part of taxpayers. The federal tax service of Russia (hereinafter FNS) has developed 109 criteria, based on which NRF staff analyze companies for signs of tax evasion. In this paper we used the criteria presented in Table 3.

Adherence of accounting information provision. According to the Article 18 of the Federal law, dated 06/12/2011 No. 402-FZ "on accounting", every economic entity obliged to compile accounting (financial) statements in 90 working days after the end of the reporting period [5], provide one instance of financial report in the State statistics bodies [7]. Failure to comply with the current requirements of the legislation may also affect the general view on the studied subject.

In addition to the above-mentioned public criteria obtained in compliance with the requirements of the Russian legislation are used, the test data sets [5] of the federal financial monitoring service (hereinafter Service Rosfinmonitoring) [6, art. 5] (the details of these transactions are generated in the form of eco (the report as an e-mail message)).

It should be noted that at present the procedure of financial statements data used by specialists of Rosfinmonitoring is regulated, but as a separate tool for evaluating the activities of economic entities. In our view, cross-usage of data and financial information of BFO transactions (deals) will significantly increase the productivity and efficiency of financial investigations, because in this case there is an opportunity for Reengineering of the base (already existing) processes of the verification activities of the notified body (Figure \# 1). The basic idea of the process is to conduct a separate analysis of the financial statements articles and banking operations, which provide information to the authorized body and further comparison of the results obtained. During the reengineering of the entire process it has been requested to provide a set of five sub-processes, which in turn will consist of a set of simple procedures. As each sub-process is realized "integrity" points are formed which are then aggregated to a certain "risk zone".

\section{Sub-process no. 1 "logon process"}

This sub-process is aimed at monitoring compliance with the undertakings providing the regime of reporting information to the government authorities in accordance with the requirements of the legislation of the Russian Federation. The current procedure 
for monitoring the provision of BFO objects of economic activity are not able to fully control the execution of the requirements of the law in part of their reporting. Therefore, enterprises have a real opportunity to carry out their activities, not performing in full the financial reporting requirements.

\section{Sub-process no. 2 "analysis of BFO and NACE codes of a company"}

\section{Procedure no. 1}

In the first procedure accounting (financial) statements are examined by using the indicators, which are aimed at identifying the distortion data and an assessment of the ACCOUNTING and FINANCE DEPARTMENT of the General status of the company (table 2). For this procedure, criteria for assessing financial statements for both public and non-public companies are developed.

\section{Procedure no. 2}

This procedure is uniform for all companies and consists of defining a code of OKVED for extract from the UNIFIED STATE REGISTER and further comparison of main OKVED with the additional one. This work used a selective approach to the definition of additional codes to reduce scan time of one company. To do this, all organizations were divided into four groups: micro, small, medium and large, depending on the target revenue of the preceding reporting period [8]. The sample size for the first group amounted to a value of " $1+3$ ", where " 1 "-"key (binding) element of the sample (the main OKVED of the company), and the" 3 "is the number of elements from the general aggregate (minus key element), which falls into material selection. For the second group number of items amounted to " 6 " for the third " 8 " and for the fourth-" 10 ". The selection of items from the general aggregate was calculated using the random number generator (random number generator [electronic resource] URL: http://randstuff.ru/number/ (date of circulation 20.03.2015)).

\section{Procedure no. 3}

After selecting codes NACE a list of typical operations was formulated that can be performed basing on the formalism of each NACE. In addition, such operations are 
committed by companies, regardless of the specific activities (getting/repayment; purchase/sale of foreign currency, etc.).

\section{Sub-process no. 3 "ECO" Analyses (report in form of an e-mail message)}

\section{Order No. 1-2}

The ECO of the company is downloaded from the Rosfinmonitoring database for the period under consideration. In this work adapted scientific-research works of ECO were used that fall under mandatory control of Service operations, as well as from internal control for the last month of the reporting period. Subsequently, the data is grouped by types of ECO codes in accordance with Annex 8 of CBR Appendix No. 321-b [9]. In the real world the most efficient results are achieved by analyzing all incoming ECO without dividing them into controls.

\section{Procedure no. 3}

In the course of this procedure for each group a list of common "language" of transactions was allocated (for example: getting an interest-free loan, the purchase of foreign currency to pay for goods, etc.). This procedure also includes an initial assessment of the ECO on their suspicions and a count of the total number of operations that correspond to NACE codes and operations specific to each business.

\section{Sub-process no. 4 "mapping"}

When comparing information breakdown of the results occurs in the following categories: comparison of the sub-process no. 2 and no. 3 of the sub-process confirmed (refuted) suspicion/operations;

It should be noted that, as the treatment process is carried out scoping "suspicion" companies. In the course of mapping the status of ECO can be changed, previously defined as "suspicious". 


\section{Sub-process no. 5 "Assessment of the obtained results"}

During the operation the final number of the points scored by the companies is determined. That is the basis for the final decision on the advisability of further verification of the organization.

\section{Process Implementation Sample}

The proposed process was created for the benefit of the federal financial monitoring service as one of the tools for testing activities in the organizations involved in State Defence Order (GOZ). So for the process testing enterprises, the real entities of public contracts were selected (customer: Ministry of Defense of the Russian Federation). As the objects of research the contracts executable on the three pillars, namely: works, goods and services were selected. In total, for the analysis of these categories 30 contracts have been selected (10 for each activity). Public procurement official site has been used as a source of information [15]. Selection is made based on the following criteria:

Transaction amount over 2500000 rub.

Year of order-2013.

The counterparty's domicile-Moscow.

Further reporting information was collected (BFO) using SPARC information database [16].

Then for each company an individual dossier was formed and the data were written in the summary table, which assessed the degree of companies conditioned to participate in suspicious transactions. Summary table consists of multiple blocks: "adherence deposit of BFO, BFO analysis", "signs of FTS", «NACE» and «ECO» (table 1). A separate analysis was made in each section with the registration of the final score.

In column 4 "Score" quantitative values are presented that are added to the final results (column 3), if there are any signs that are listed in the column "Indicator" (column 2). At the end of the sub-process a final payment is made and is written in the row "Total".

Following the second procedure the calculation of the sub-process analysis criteria was selected for. The final results of the calculations are presented in table no. 2 "BFO" Analysis. 
TABLE 1: Example of the table.

\begin{tabular}{|c|c|c|c|}
\hline 1 & 2 & 3 & 4 \\
\hline & Indicator & Response & Score \\
\hline \multirow{4}{*}{$\begin{array}{l}\text { Adherence } \\
\text { deposit of BFO }\end{array}$} & Are in stock & & 0 \\
\hline & Absent for 2 years or more & & 1 \\
\hline & The company created in the analyzed period & & 3 \\
\hline & Missing reporting & & 2 \\
\hline $\begin{array}{l}\text { Analysis of The } \\
\text { ACCOUNTING And } \\
\text { FINANCE } \\
\text { DEPARTMENT }\end{array}$ & The number of points earned in the analysis & & - \\
\hline Signs Of FNS & The number of points earned in the analysis & & - \\
\hline \multirow[t]{5}{*}{ NACE } & Additional codes broadly correspond to the main & & 0 \\
\hline & Additional OKVED is somewhat suspicious & & 1 \\
\hline & Additional codes are not related to the main & & 2 \\
\hline & The COMPANY has not declared any NACE & & 3 \\
\hline & The BFO and ENTITIES have different main OKVED & & 1 \\
\hline \multirow[t]{5}{*}{ ECO } & No suspicious transactions (mandatory) & & 0 \\
\hline & Suspicious transactions (mandatory) & & 5 \\
\hline & $\begin{array}{l}\text { The typical kinds of operations are very many, } \\
\text { although they must be rare (mandatory) }\end{array}$ & & 5 \\
\hline & Insufficient data (mandatory) & & 2 \\
\hline & $\begin{array}{l}\text { Suspicious transactions at the end of the reporting } \\
\text { period (December) (mandatory and internal control) }\end{array}$ & & 5 \\
\hline
\end{tabular}

The following values were put next to each criterion in column "score": " 1 "-if the condition in the column "Criterion" was fulfilled, «o»-the condition has not been fulfilled, "0.5"-data was or was not enough. (This point can be scored by the criteria 2 and 4 , because in the first case, not every company had the information about its audit, and in the second case-not all organizations reportings for the previous (year 2012) are available).

To determine the points on the second criterion of the MOF a website have been used, namely the section "registry of auditing organizations" [17], with attention focused on the violations discovered during the implementation of the quality control 
TABle 2: "Example of the "BFO Analysis table".

\begin{tabular}{|c|c|c|}
\hline \multicolumn{3}{|c|}{ Analysis of The ACCOUNTING And FINANCE DEPARTMENT } \\
\hline NO. $\mathrm{p} / \mathrm{p}$ & Criteria & Score \\
\hline 1 & $\begin{array}{l}\text { A negative result on the methodology of Boenisch (The technique involves } \\
\text { the use of ratio Boenisch approach to the analysis of financial statements, in } \\
\text { particular the calculation of the rate of growth targets. On the basis of the } \\
\text { results obtained, the total is calculated } M \text {-scorethat allows you to judge the } \\
\text { quality of financial reporting.) }\end{array}$ & \\
\hline 2 & Analysis by an audit organization (SCA violations) & \\
\hline 3 & $\begin{array}{l}\text { Accuracy indicators of financial statements articles (balance sheet, profit and } \\
\text { loss statement) (a comparison of the result manually recalculate the balance } \\
\text { sheet articles to its currency, as well as report data on financial results with } \\
\text { indicators for profit organization.) }\end{array}$ & \\
\hline 4 & $\begin{array}{l}\text { Comparability of financial statements (a comparison of the data of the } \\
\text { previous reporting period, current financial statements with the same data } \\
\text { the previous financial statements.) }\end{array}$ & \\
\hline 5 & $\begin{array}{l}\text { Sharp dynamics of return on assets (a strong deviation of the values from } \\
\text { the medium-sized similar industry) }\end{array}$ & \\
\hline 6 & $\begin{array}{l}\text { Sharp dynamics of profitability of equity (a strong deviation of the values } \\
\text { from the medium-sized similar industry) }\end{array}$ & \\
\hline 7 & $\begin{array}{l}\text { Sharp dynamics of profitability of sales (strong deviation of the values from } \\
\text { the medium-sized similar industry) }\end{array}$ & \\
\hline 8 & Unusual decrease in payable turnover period & \\
\hline 9 & Unusual increase in receivable turnover period & \\
\hline 10 & The current ratio of tax revenue & \\
\hline 11 & Other income to revenue ratio & \\
\hline 12 & Negative balance on current activities amid revenue growth & \\
\hline 13 & $\begin{array}{l}\text { The value of the assets is in the range of up to } 59900000-58000000 \\
\text { rubles (for private companies) (according to article } 5 \text { FZ No. } 307 \text { on auditing } \\
\text { activity', non-public organizations are subject to obligatory audit, if the } \\
\text { amount of the assets over the preceding reporting period is over } 60000000 \\
\text { rubles. Therefore, the opportunity for a small portion of the value of space } \\
\text { assets in order to avoid compulsory audit.) }\end{array}$ & \\
\hline 14 & Sharp dynamics of intermediate liquidity & \\
\hline 15 & Sharp dynamics of current liquidity & \\
\hline 16 & $\begin{array}{l}\text { Specification of BFO articles (the presence of a large proportion of "other" } \\
\text { line in the balance sheet) }\end{array}$ & \\
\hline & Total & \\
\hline
\end{tabular}

over the activities of the members of the SOA (self-regulatory organization of auditors). As a result, companies can score: "o" points if violations were not found, "1" score-if violations were found. In summing up of the results the following was found: 
The most common criteria were "negative results on Benishe methodology" and "sharp dynamics of profitability of own capital. It was found in $43 \%$ of companies.

In $23 \%$ of the studied organizations a violation of criterion "accuracy of indicators of financial statements articles (balance sheet, profit and loss statement) was found."

$20 \%$ of organizations have an infringement of the "criterion of comparability of financial statements.

In the next block analysis of companies was made on the grounds of unconscionability, developed by the federal tax service (table 3). If there is a sign in the column labeled "Score" " 1 " was written. If the data were insufficient or controversial (contradictory) "0.5". If the signs are not detected: "o".

TABLE 3: "Summary table of analysis based on FTS".

\begin{tabular}{|c|c|c|c|}
\hline NO. $p / p$ & $\begin{array}{l}\text { Source of } \\
\text { information }\end{array}$ & Signs & Points \\
\hline 1 & SPARK & $\begin{array}{l}\text { Company registration address is the address of the "mass" } \\
\text { registration }\end{array}$ & \\
\hline 2 & $\begin{array}{l}\text { Information } \\
\text { resources }\end{array}$ & Company registration address does not exist & \\
\hline 3 & $\begin{array}{l}\text { LEGAL ENTITIES, } \\
\text { Contour Focus }\end{array}$ & $\begin{array}{l}\text { NAT. person is the founder of } 10 \text { or more companies } \\
\text { ("bulk" founder) }\end{array}$ & \\
\hline 4 & LEGAL ENTITIES & The company is registered as a limited liability company & \\
\hline 5 & LEGAL ENTITIES & $\begin{array}{l}\text { Frequent change (more than } 1 \text { time per month) place of } \\
\text { tax registration }\end{array}$ & \\
\hline 6 & SPARK & $\begin{array}{l}\text { The company does not report (information on headcount) } \\
\text { in statistical agencies }\end{array}$ & \\
\hline 7 & BFO & $\begin{array}{l}\text { The company lacked basic facilities necessary for activities } \\
\text { (transportation, warehouse, retail outlets, etc.) }\end{array}$ & \\
\hline 8 & BFO & $\begin{array}{l}\text { The growth rate of sales expenses compared to the same } \\
\text { period of the previous year, significantly higher than the } \\
\text { growth rate of revenues from the sale }\end{array}$ & \\
\hline 9 & BFO & The company tax burden decreases amid revenue growth & \\
\hline 10 & BFO & $\begin{array}{l}\text { The taxpayer primarily reflects the loss in accounting or } \\
\text { tax reporting }\end{array}$ & \\
\hline
\end{tabular}

Rate of total rows in the table no. 3 was transferred to the summary table "signs of FNS. Based on the results of this procedure, it was found that the most fulfilled criterion was number 4 "company is registered as a limited liability company", it can be found in $67 \%$ of companies; second place went to the criterion "the company's registered address is the address of the" mass "registration"-50\%, respectively. 
The next procedure is carried out in comparison with main NACE additional codes. When you do this, if the specifics of the first greatly differed from the second, this fact is taken into account when summing up the results of the second of the sub-process. Further results were transferred to in the summary table "NACE". It was established:

1. $10 \%$ of the analyzed companies upon registration generally did not specify OKVED.

2. $13 \%$ of the companies in financial reporting and LEGAL ENTITIES specified different main NACE codes.

3. $23 \%$ of organizations have additional OKVED codes, which in no way related to the main.

However, in $40 \%$ of companies no "suspicious" signs have been identified.

In order to analyze further a list of typical operations has been compiled, classified according to NACE codes and to complete the classification operations were added that are specific to each company.

The following subprocess, ECO analysis, consists of three procedures:

1. downloading ECO of the companies for the analyzed period;

2. sorting the ECO codes;

3. identifying each group of codes common for the analyzed operations.

It was noted, in general, in the course of verification operation codes 4005, 4006, 5003,5007 were met most often. And the extent of their "suspicion" could be judged based on the frequency of operations, characteristic of any business, so on the basis of previously defined operations for each NACE. If the operations that do not fall into any predefined criterion (taking into account the nature of the operation):

1. during comparison financial statements were analysed confirming the made transaction (receiving a large amount of borrowed money; buying/selling land; expensive purchase/sale of securities, etc.);

2. in case of impossibility of performance of the first paragraph of this operation it was referred to the category of "suspect".

Also when matching operations were detected to interpret unambiguously the value was impossible because there was no accurate description of them (23\%). 


\section{Evaluation of the effectiveness of the process. Recommendations for its improvement}

It is anticipated that the process will be the first step in the evaluation of companies, on the basis of which a decision will be taken of a more detailed inspection. In August of 2015 Rosfinmonitoring established a new office for dealing with fiscal management, whose main task is to identify the facts of misuse of budget funds in the performance of the State Defense order and their legalization through a number of fictitious companies. The process proposed in this paper, can become one of the initial or confirmatory methods for evaluating companies, because in the near future it is expected that the established Office would broaden the scope of its competences to cover the entire budgetary sector.

To assess the effectiveness of the proposed process a partial SWOT-analysis was made, the results of which are presented in table 4 .

TABLE 4: "The results of the SWOT analysis of the elaborated process".

\begin{tabular}{l|l|l} 
NO. p/P & Advantages & Disadvantages \\
\hline 1 & There is no strict sequence of actions & Duration of inspection of one company \\
\hline 2 & $\begin{array}{l}\text { The ability to use separate } \\
\text { sub-processes }\end{array}$ & $\begin{array}{l}\text { Manual enumeration of typical } \\
\text { operations for each code of OKVED }\end{array}$ \\
\hline 3 & Distribution of companies by "risk areas" & Limited access to ECO \\
\hline 4 & $\begin{array}{l}\text { The opportunity to add to the overall } \\
\text { structure of the new subprocesses or } \\
\text { procedures }\end{array}$ \\
\hline 5 & $\begin{array}{l}\text { Possible variability of the point } \\
\text { evaluation of companies }\end{array}$
\end{tabular}

Depending on what source of information for the reviewer is paramount (accounting (financial) statements or eco) and which is confirming can vary the sequence of the process. In other words, the process can be performed in reverse: first the ECO of the organizations can be evaluated, with the selection of these typical and atypical company operations, and only then data is placed in the financial reporting.

In addition, part of the process, limited analysis of subprocesses "logon process", "analysis of the BFO and NACE codes, can be used by commercial organizations to validate new counterparties and for the assessment of the past ones, which also contributes to enhancing the effectiveness of the internal controls of the economic entity [14]. In order to optimize streaming analysis procedures information transactions in the ECO service can use the following procedures: extract from the UNIFIED STATE REGISTER 
of operations themselves, entering the Service, i.e. in fact only five procedures process can be used: in the second subprocess procedure 2 and 3 , and the full third sub-process. Thus, depending on who uses a developed process and what his aim is the number of procedures can be changed. However, the full picture gives a complex application, as the original purpose of creating process-identifying signs of legalization of monetary means when comparing financial statements data and the ECO organizations.

Based on the foregoing, the following conclusion can be drawn: the results obtained in implementing the described procedures, demonstrated the effectiveness of the developed process in AML/CFT. At the same time, according to the results of the testing of the proposed process, it was found that the time required for its implementation is significant and needs to be optimized. It therefore seems expedient to make partial automation of individual processes that are described in this paper:

1. "Logon process".

2. "Analysis of the BFO and NACE codes.

3. "ECO" analyses.

As mentioned above, the volume of information iused in the process is limited. When this restriction is due to the mobility of the analyst and the relatively low degree of automation. However, the amount of information in part of the ECO for every business today is so great that even the proposed automation technique will not allow the "digestible" time to handle it. It therefore seems desirable to explore the possibility of using additional tools to analyze the full array of the ECO.

In addition, substantial methodological improvements will be to add subprocesses to process in processing of tax returns as an additional information resource.

\section{Conclusion}

The proposed innovation reengineering activities will subsequently create a decisionmaking system for the implementation of the AML/CFT. Because one component of such a system should be database "examples" of legalization available information on organizations must be processed on the proposed methodology, unlawful activities of which are already proven.

Within the continuous improvement of the proposed process, of course, waivers of certain criteria are possible and as well as the involvement of new ones, developed during the accumulation of statistical data. 


\section{Acknowledgements}

This work was supported by Competitiveness Growth Program of the Federal Autonomous Educational Institution of Higher Education National Research Nuclear University MEPhl (Moscow Engineering Physics Institute).

\section{References}

[1] Order of the Ministry of finance from 02.07.2010 N 66 n. (ed. 06.04.2015) "on the forms of accounting organizations.

[2] Federal auditing standard 7/2011 of the Finance Ministry of Russia Ordered FSAD, dated July 16 no. h 99

[3] Russian economic crime survey of 2014 [electronic resource] URL: http://www.pwc.ru/ru/ceo-survey/assets/crime_survey_2014.pdf (date of circulation 05.08.2017)

[4] Federal Law No. 129-FZ "about the State registration of legal entities and individual entrepreneurs", Newsletter No. 100 of the Presidium of the Supreme Arbitration Court of the Russian Federation, dated 17.01.2006. decision No. 454-St. Adopting and enacting OKVED, adopted the State Committee of the Russian Federation for standardization and methodology 06.11. 2001

[5] art. 26 of the Federal Law "on banks and banking activities" from 02.12.1990 N 395-1

[6] Federal law dated August no. 115-FZ (red. 31.12.2014) "on counteracting the legalization (laundering) of proceeds received by criminal way and terrorism financing".

[7] The Federal Law, dated 06.12.2011 No. 402-FZ "on accounting".

[8] Decree of the Government of the Russian Federation, dated 09.02.2013 \# 101 "on limit values for proceeds from realization of goods (works, services) for each category of small and medium-sized businesses.

[9] The position of the Central Bank of the Russian Federation, dated 29.08.2008 No. 321-p "on the procedure for the submission of credit institutions to the competent authority the information specified in the Federal law" on counteracting the legalization (laundering) of proceeds received by criminal way and terrorism financing".

[10] Order of the Ministry of Finance of the Russian Federation, dated 06.07.1999 N $43 \mathrm{n}$. (red. from 08/11/2010) "on approval of the regulations on accounting «accounting organization (COA 4/99). 
[11] Leonov P.Y. Selective methods of testing control procedures in the organization of quality control system of internal control. [Text]/Leonov P.Y. audit and financial analysis of MPA press LLC, 2012. No. 4. C. 220-223.

[12] J.A. Kevorkova distortion of financial statements as a sign of economic crime. Analytical Portal "Industry 2015 right.".

[13] Nasonov E.V., Vavilov M.S. the review of the Russian market for offshore services in the context of the economic status of offshore territories//business law No. 5/2014: economic-legal journal; ed. House «Jur-WAC, 2014, with 252.

[14] Leonov P.Y. Perspective assessment of the quality of the internal control system. [Text]/Leonov P.Y. Financial Analytics: problems and solutions. LLC "EID" Finance and credit "Bank, 2013. No. 15. S. 38-42.

[15] Official website of the Russian Federation on the Internet for posting information about placing orders for the supply of goods, works and services [electronic resource] URL:http://zakupki.gov.ru (15.02.2017).

[16] Electronic SPARK database [electronic resource] URL:http://.spark.interfax.ru (17.05.2017 treatment).

[17] Official website of the Ministry of Finance of the Russian Federation [electronic resource] URL: http://www.minfin.ru/ru/perfomance/audit/reestr_audit/ auditor_org/index .php?org_name=\&OPF=\&Terr=\&sro=\&or $z n=\& o g r n=$. 